\title{
Efficacy and safety of nebivolol in Korean patients with hypertension by age and sex: a subanalysis from the BENEFIT-KOREA study
}

Kyoung Im Cho ${ }^{1 \wedge}$, Dong Woon Jeon ${ }^{2 *}$, Hyo Seung Ahn ${ }^{3}$, Dong Kyu Jin ${ }^{4}$, Hyun Sang Lee ${ }^{5}$, Jong-Young Lee ${ }^{6}$, Hong-Seok Lim, Athanasios J. Manolis ${ }^{8}$, Seung-Woon Rha ${ }^{9}$ and Sang Won Park ${ }^{10}$

\begin{abstract}
Background: BENEFIT-KOREA (BEnefits after 24 weeks of NEbivolol administration For essential hypertenslon patients wiTh various comorbidities and treatment environments in Korea) study, an observational study in South Korea, demonstrated the efficacy and safety of nebivolol in Asian patients with essential hypertension with and without comorbidities in real-world settings. We present a subanalysis of the efficacy and safety of nebivolol across age and sex in the BENEFIT-KOREA cohort.

Methods: Adult South Korean patients with essential hypertension participated in the prospective, single-arm, open, observational BENEFIT-KOREA study; 3011 patients received nebivolol as monotherapy or add-on therapy. Changes in systolic blood pressure (SBP) and diastolic blood pressure (DBP), and pulse rate at 12 and 24 weeks were evaluated. Participants were divided into three age groups-young males and females: $<50$ years; middleaged males and females: $\geq 50$ years to $<70$ years; and older males and females: $\geq 70$ years.
\end{abstract}

Results: The mean age of study participants was $63.5 \pm 12.9$ years; majority were between 50 and 69 years of age and $40.4 \%$ were females. A significant decrease was observed in mean SBP, DBP, and pulse rate from baseline at 12 and 24 weeks in males and females across all age groups analyzed (all $P<0.001$ vs. baseline), with no significant difference in mean reduction in SBP and DBP from baseline between sex within the age groups. Majority of reported adverse events were mild. The incidence of adverse events was lower in young participants versus middleaged and older participants.

Conclusions: Our subanalysis from the real-world BENEFIT-KOREA study in Asian patients with essential hypertension demonstrated the efficacy and safety of once-daily nebivolol across age groups with no between-sex differences.

Trial registration: Name of the registry: clinicaltrials.gov. Trial registration number: NCT03847350. Date of registration: February 20, 2019 retrospectively registered.

Keywords: Essential hypertension, Nebivolol, Asian, Monotherapy, Combination therapy, Add-on therapy, Age, Sex

\footnotetext{
* Correspondence: jdw121620@naver.com

Kyoung Im Cho is deceased.

2Division of Cardiology, National Health Insurance Service Ilsan Hospital,

Goyang, Republic of Korea

Full list of author information is available at the end of the article
}

(c) The Author(s). 2021 Open Access This article is licensed under a Creative Commons Attribution 4.0 International License, which permits use, sharing, adaptation, distribution and reproduction in any medium or format, as long as you give appropriate credit to the original author(s) and the source, provide a link to the Creative Commons licence, and indicate if changes were made. The images or other third party material in this article are included in the article's Creative Commons licence, unless indicated otherwise in a credit line to the material. If material is not included in the article's Creative Commons licence and your intended use is not permitted by statutory regulation or exceeds the permitted use, you will need to obtain permission directly from the copyright holder. To view a copy of this licence, visit http://creativecommons.org/licenses/by/4.0/ The Creative Commons Public Domain Dedication waiver (http://creativecommons.org/publicdomain/zero/1.0/) applies to the data made available in this article, unless otherwise stated in a credit line to the data. 


\section{Background}

Hypertension, the most common modifiable risk factor for all-cause mortality and morbidity worldwide, is a widespread public health challenge; approximately 1 billion people or $26 \%$ of the world population suffers from hypertension $[1,2]$. The prevalence of hypertension is known to differ by age, sex, and other factors [3, 4] and it increases with advancing age $[5,6] ; \sim 60 \%$ older adults become hypertensive [7].

Several studies have shown a higher prevalence of hypertension in males $<65$ years of age compared with females of the same age group; however, in the sixth decade of life and beyond, the prevalence of hypertension becomes higher in females than in males [4, 8-11]. Similar data has been reported in Korean adults. In the Korean National Health and Nutrition Examination Survey (KNHANES) 2016, the prevalence of hypertension in adults between the age of 60-69 years and those $\geq 70$ years was 51 and $69 \%$, respectively [12]. The prevalence was higher in males (56\%) than in females (46\%) until the age of 60 years, but lower in males (64\%) than in females (72\%) after the age of 70 years [12]. Korean females $>60$ years of age were more likely to have hypertension and less likely to maintain hypertension control than males in the same age group [3].

Observed sex-based differences in hypertension could be attributed to biological and behavioral differences between the sexes [13]. For instance, the sympathetic nervous system has a dynamic role in blood pressure (BP) maintenance and in the pathogenesis of hypertension $[14,15]$. It changes with age and may have different extent of contribution for hypertension development in males and females [14, 15]. Despite sex differences in hypertension, the treatment guidelines for hypertension do not differ by sex [4].

Nebivolol is a vasodilatory $\beta 1$-adrenergic receptor antagonist which has been reported to be efficacious and well tolerated for achieving BP control in patients with hypertension [16]. The BENEFIT-KOREA (BEnefits after 24 weeks of NEbivolol administration For essential hypertensIon patients wiTh various comorbidities and treatment environments in Korea) study, a noncomparative, non-controlled, prospective, single-arm, multicenter, observational study conducted at 66 sites in South Korea, demonstrated the efficacy and safety of nebivolol in Asian patients with essential hypertension with and without comorbidities in a real-world setting [17]. In this manuscript, we report the results of a subanalysis of the efficacy and safety of nebivolol across age and sex in the BENEFIT-KOREA cohort.

\section{Methods}

Details of the study design and methodology are available in the primary manuscript of the BENEFIT-Korea study [17]. The study was conducted in accordance with the ethical principles that have their origins in the Declaration of Helsinki. All enrolled patients provided written informed consent prior to undergoing any studyrelated procedure. The study protocol and relevant documentation were approved by Institutional Review Board/independent ethics committee(s).

In brief, the BENEFIT-KOREA study was an open, non-comparative, non-controlled, prospective, singlearm, multicenter observational study which enrolled

Table 1 Study visit schedule: BENEFIT-Korea study

\begin{tabular}{|c|c|c|c|}
\hline Variable & Visit 1 (baseline) & Visit 2 (follow-up) & Visit 3 (follow-up/last visit) \\
\hline Schedule (wk) & 0 & $12 \pm 2^{a}$ & $24 \pm 2^{a}$ \\
\hline Informed consent form & $\sqrt{ }$ & & \\
\hline Inclusion/exclusion criteria & $\sqrt{ }$ & & \\
\hline Patient demographics & $\sqrt{ }$ & & \\
\hline Height/weight/waist size ${ }^{b}$ & $\sqrt{ }$ & $\sqrt{ }$ & $\sqrt{ }$ \\
\hline History of previous anti-hypertensive drugs & $\sqrt{ }$ & & \\
\hline Medical history ${ }^{c}$ & $\sqrt{ }$ & & \\
\hline Administrative status of nebivolol & $\sqrt{ }$ & $\sqrt{ }$ & $\sqrt{ }$ \\
\hline Concomitant medications & $\sqrt{ }$ & $\sqrt{ }$ & $\sqrt{ }$ \\
\hline Laboratory test $^{\mathrm{d}}$ & $\sqrt{ }$ & $\sqrt{ }$ & $\sqrt{ }$ \\
\hline Blood pressure measure & $\sqrt{ }$ & $\sqrt{ }$ & $\sqrt{ }$ \\
\hline Safety assessment & & $\sqrt{ }$ & $\sqrt{ }$ \\
\hline
\end{tabular}

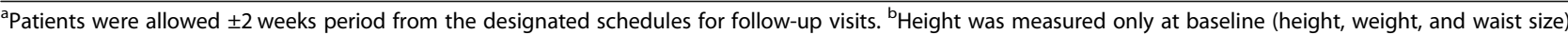
was recorded up to one decimal. 'Past medical history and present medical history within 6 months from baseline were recorded. In case a medical history was collected after baseline, it was recorded in the safety analysis set. ${ }^{\mathrm{d}}$ Glucose (HbA1c, fasting blood sugar), total cholesterol, triglyceride, high density lipoprotein cholesterol, low density lipoprotein cholesterol, and other laboratory tests, when done, were recorded. Of the laboratory test results collected, the values pointing

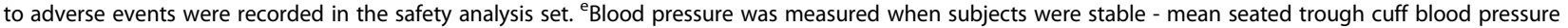
was measured 
male and female patients $\geq 19$ years diagnosed with essential hypertension. These patients could be newly diagnosed with hypertension and not receiving any antihypertensives, or previously diagnosed and receiving other anti-hypertensives, making a switch to nebivolol as combination or add-on therapy. The visit schedule is outlined in Table 1.

BP was measured based on guidelines from the Korean Society of Hypertension [18] and was in accordance with the European Society of Cardiology/ European Society of Hypertension (ESC/ESH) guidelines. All participating centers were checked for compliance and the settings for $\mathrm{BP}$ measurement defined in the protocol at the initiation meeting. BP was measured when patients were in stable state with 5 min rest. The mean seated cuff BP was measured twice within 1-min interval using upper arm sphygmomanometer; either manual or automated device was permitted. BP measurements were recorded and presented as an average of two measurements. Pulse rate reading generated by automated device or pulse rate measured for $15 \mathrm{~s}$ before manual measurement multiplied by four were regarded as the pulse rate per minute. Site feasibility was checked and confirmed before study initiation to ensure study compliance.

Table 2 Baseline patient demographics: safety population BENEFIT-Korea study

\begin{tabular}{|c|c|c|c|}
\hline Variable & Male $(n=1871)$ & Female $(n=1269)$ & Total $(n=3140)$ \\
\hline \multicolumn{4}{|l|}{ Age (yr) } \\
\hline$<50$ & $359(11.4)$ & $124(4.0)$ & $483(15.4)$ \\
\hline $50-69$ & $976(31.1)$ & $508(16.2)$ & $1484(47.3)$ \\
\hline$\geq 70$ & $536(17.1)$ & $637(20.3)$ & $1173(37.4)$ \\
\hline Height $(\mathrm{cm})^{a}$ & $168.7 \pm 6.7$ & $154.2 \pm 6.1$ & $162.7 \pm 9.6$ \\
\hline Body weight $(\mathrm{kg})^{\mathrm{b}}$ & $73.4 \pm 12.5$ & $60.8 \pm 10.2$ & $68.1 \pm 13.2$ \\
\hline Waist circumference $(\mathrm{cm})^{c}$ & $90.0 \pm 9.0$ & $84.4 \pm 9.6$ & $87.7 \pm 9.6$ \\
\hline BMI $\left(\mathrm{kg} / \mathrm{m}^{2}\right)^{\mathrm{d}}$ & $25.7 \pm 3.5$ & $25.5 \pm 4.0$ & $25.6 \pm 3.8$ \\
\hline Cardiocerebrovascular risk factors present & $1825(97.5)$ & $1192(93.9)$ & $3017(96.1)$ \\
\hline Male $\geq 45 \mathrm{yr}$, female $\geq 55 \mathrm{yr}$ & $1643(90.0)$ & $1064(89.3)$ & $2707(89.7)$ \\
\hline Current smoker & $451(24.7)$ & $21(1.8)$ & $472(15.6)$ \\
\hline $\mathrm{BMI} \geq 25 \mathrm{~kg} / \mathrm{m}^{2}$, or waist circumference $>90 \mathrm{~cm}$ (male) or $>80 \mathrm{~cm}$ (female) & $673(36.9)$ & $455(38.2)$ & $1128(37.4)$ \\
\hline Dyslipidemia & $911(49.9)$ & $613(51.4)$ & $1524(50.5)$ \\
\hline Impaired fasting glucose or impaired glucose tolerance & $42(2.3)$ & $15(1.3)$ & $57(1.9)$ \\
\hline Family history of early cardiocerebrovascular disease (male, $<55 \mathrm{yr}$, female $<65 \mathrm{yr}$ ) & $84(4.6)$ & $69(5.8)$ & $153(5.1)$ \\
\hline Diabetes mellitus & $549(30.1)$ & $323(27.1)$ & $872(28.9)$ \\
\hline Medical history present & $1667(89.1)$ & $1131(89.1)$ & $2798(89.1)$ \\
\hline Diseases of circulatory system & $1234(74.0)$ & $773(68.4)$ & $2007(71.7)$ \\
\hline Endocrine, nutritional and metabolic diseases & $1045(62.7)$ & $713(63.0)$ & $1758(62.8)$ \\
\hline Diseases of genitourinary system & $276(16.6)$ & $123(10.9)$ & $399(14.3)$ \\
\hline Diseases of digestive system & $138(8.3)$ & $140(12.4)$ & $278(9.9)$ \\
\hline Diseases of musculoskeletal system and connective tissue & $98(5.9)$ & $111(9.8)$ & $209(7.5)$ \\
\hline Use of concomitant treatment with anti-hypertensives with nebivolol & $1460(78.0)$ & $984(77.5)$ & $2444(77.8)$ \\
\hline Calcium antagonists & $816(55.9)$ & $512(52.0)$ & $1328(54.3)$ \\
\hline Angiotensin II receptor antagonists & $724(49.6)$ & $583(59.3)$ & $1307(53.5)$ \\
\hline Diuretics & $299(20.5)$ & $279(28.4)$ & $578(23.7)$ \\
\hline ACE inhibitors & $183(12.5)$ & $42(4.3)$ & $225(9.2)$ \\
\hline Alpha-blockers & $24(1.6)$ & $9(0.9)$ & $33(1.4)$ \\
\hline Not available & $10(0.7)$ & $2(0.2)$ & $12(0.5)$ \\
\hline
\end{tabular}

Values are presented as number (\%) or mean \pm standard deviation

$P$-value (t-test) for the difference between male and female was significant $(P<0.001)$ for height, weight, and waist circumference

$B M I$ body mass index, $A C E$ angiotensin-converting enzyme

${ }^{a}$ Height measurement: male (1217), female (867). ${ }^{b}$ Body weight measurement: male (1212), female (868). ${ }^{\mathrm{c}}$ Waist circumference: male (292), female (208). ${ }^{\mathrm{d} B M I:}$ male (1174), female (846) 
A
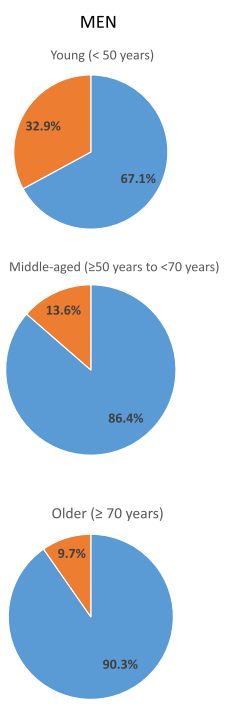

- YES $=$ NO
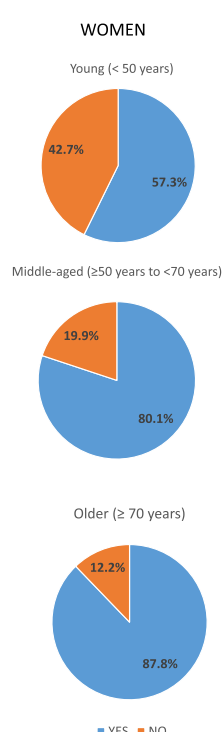

B

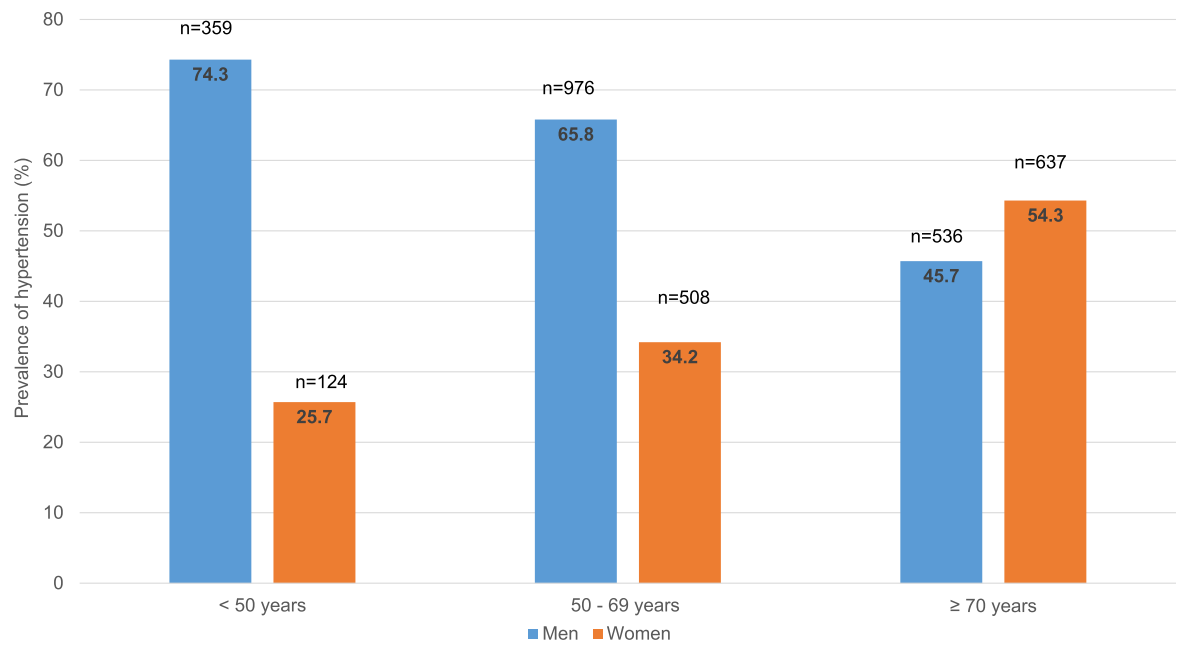

Fig. 1 a Concomitant medications (other than anti-hypertensives) by age and sex in the safety population in the BENEFIT-Korea study; b Prevalence of hypertension by sex and age in the safety population in the BENEFIT-Korea study

Primary and secondary end points of the BENEFITKOREA study have been presented by Lee et al. [18] In this manuscript, we present the results of a subanalysis of the participants for change in systolic BP (SBP) and diastolic BP (DBP) and pulse rate after 12 and 24 weeks of nebivolol treatment based on age and sex.

The safety set was defined as all participants who were administered nebivolol and underwent followup at least once during the study period. Efficacy parameters were analyzed in the efficacy set defined as all participants from the safety set who also had efficacy assessment data at 12 or 24 weeks. All statistical analyses were performed using SAS ver. 9.4 (SAS
Institute Inc., Cary, NC, USA). Quantitative data were statistically analyzed using paired t-test. Safety endpoints of treatment emergent adverse events were assessed using the Medical Dictionary for Regulatory Activities (MedDRA) standardized terms.

\section{Results}

Baseline demographics and clinical characteristics

Of the 3250 participants enrolled in the data from 66 sites across South Korea, 3140 were included in the safety set. The efficacy set included 3011 participants, 129 participants whose SBP and DBP were not recorded at baseline or at 12 ( \pm 2 weeks) or 24 weeks ( \pm 2 weeks) were excluded from the safety set. 
Baseline demographics and the clinical characteristics of the safety population are summarized in Table 2 . The mean age of study participants was $63.5 \pm 12.9$ years; majority of the participants were between 50 and 69 years of age and $40.4 \%$ were females. Cardiocerebrovascular risk factors were present in a higher proportion of males $(97.5 \%)$ versus females $(93.9 \%)$ and more males were current smokers compared with females $(24.7 \%$ vs. $1.8 \%)$ (Table 2). The use of concomitant medications other than anti-hypertensives increased with age in both males and females (Fig. 1a).

For the age and sex analysis, the participants were divided into three age groups-young males and females, < 50 years; middle-aged males and females, $\geq 50$ years to $<70$ years; and older males and females, $\geq 70$ years. The categorization of older adults is in line with the SENIORS study population where the effect of nebivolol was assessed in elderly patients ( $\geq 70$ years) with heart failure [19].

The prevalence of hypertension in the BENEFITKOREA study population is illustrated in Fig. 1b; the prevalence of hypertension increased in females with increasing age and was higher in females than in males in the older age group.

The total dose of nebivolol was significantly lower in females compared with males $(P<0.001)$ and in older participants compared with middle-aged and young participants $(<50$ years, $P<0.001 ; 50-69$ years, $P<0.001$ ) (Table 3).

\section{Subanalysis outcomes}

There was a significant decrease in mean SBP and DBP from baseline at 12 and 24 weeks in both males and females and across all age groups analyzed (all $P<0.001$ vs. baseline) (Fig. 2a, b). Within the age groups, there was no significant difference in mean reduction in SBP and DBP from baseline between sexes. Similarly, a significant decrease in mean pulse rate from baseline was observed at 12 and 24 weeks in males and females across all age groups analyzed (all $P<0.001$ vs. baseline) (Fig. 3).

Dizziness, headache, chest pain/discomfort, and dyspnea were the most frequently reported adverse events (Table S1). Majority of the reported adverse events were mild. The incidence of adverse events and adverse drug reactions was lower in young males and females participants compared with middle-aged and older participants (Table 4, Table S2).

\section{Discussion}

In this subanalysis of the efficacy and safety of nebivolol across age and sex in the BENEFIT-KOREA cohort, we observed a significant decrease in the mean SBP and DBP from baseline in both sexes and across all age groups of participants with essential hypertension, with nebivolol demonstrating an acceptable safety and tolerability profile.

Beta-blockers are considered suitable for the treatment of essential hypertension and are currently recommended for the treatment of hypertension, even in older patients, by the ESC/ESH guidelines [5]. Similar to other classes of anti-hypertensives, beta-blockers have been shown to significantly reduce the risk of stroke, heart failure and major cardiovascular events in younger and older patients with hypertension, although their effectiveness has been shown to be age-dependent [20]. Nebivolol is a third-generation vasodilatory $\beta 1$-adrenergic receptor antagonist which induces nitric oxide-mediated vasodilatory effects via $\beta 3$ receptor agonism and has demonstrated similar or better treatment response and BP control compared with other anti-hypertensives or their combinations, with significantly better tolerability $[21,22]$.

Table 3 Average daily dose and total dose of nebivolol in the safety population in BENEFIT-Korea study

\begin{tabular}{|c|c|c|c|c|}
\hline Dose (mg) & Male $(n=1871)$ & Female $(n=1269)$ & Total $(n=3140)$ & $P$-value \\
\hline Average daily dose of nebivolol & $4.5 \pm 0.99$ & $4.4 \pm 1.1$ & $4.5 \pm 1.0$ & \\
\hline Total dose of nebivolol & $792.1 \pm 269.4$ & $747.3 \pm 290.1$ & $774.0 \pm 278.7$ & $<0.001^{\mathrm{a}}$ \\
\hline \multicolumn{5}{|l|}{ Total dose of nebivolol by age (yr) } \\
\hline$<50$ & - & - & $818.5 \pm 258.8$ & $0.44^{\mathrm{b}}$ \\
\hline $50-69$ & - & - & $800.9 \pm 270.8$ & $<0.001^{c}$ \\
\hline$\geq 70$ & - & - & $721.6 \pm 288.6$ & $<0.001^{\mathrm{d}}$ \\
\hline \multicolumn{5}{|c|}{ Average daily dose of nebivolol by age (yr) } \\
\hline$<50$ & - & - & $4.8 \pm 0.6$ & \\
\hline $50-69$ & - & - & $4.6 \pm 1.0$ & \\
\hline$\geq 70$ & - & - & $4.2 \pm 1.2$ & \\
\hline
\end{tabular}

Values are presented as mean \pm standard deviation. Average daily dose of nebivolol = total dose of nebivolol / total treatment period; total dose of nebivolol $=$ total dose of nebivolol $X$ treatment period

Wilcoxon rank sum test; comparison between males and females. ${ }^{b}$ Wilcoxon rank sum test, comparison between $<50$ years and $50-69$ years. ${ }^{\mathrm{C}}$ Wilcoxon rank sum test; comparison between 50 and 69 years and $\geq 70$ years. ${ }^{d}$ Wilcoxon rank sum test; comparison between $<50$ years and $\geq 70$ years 
A
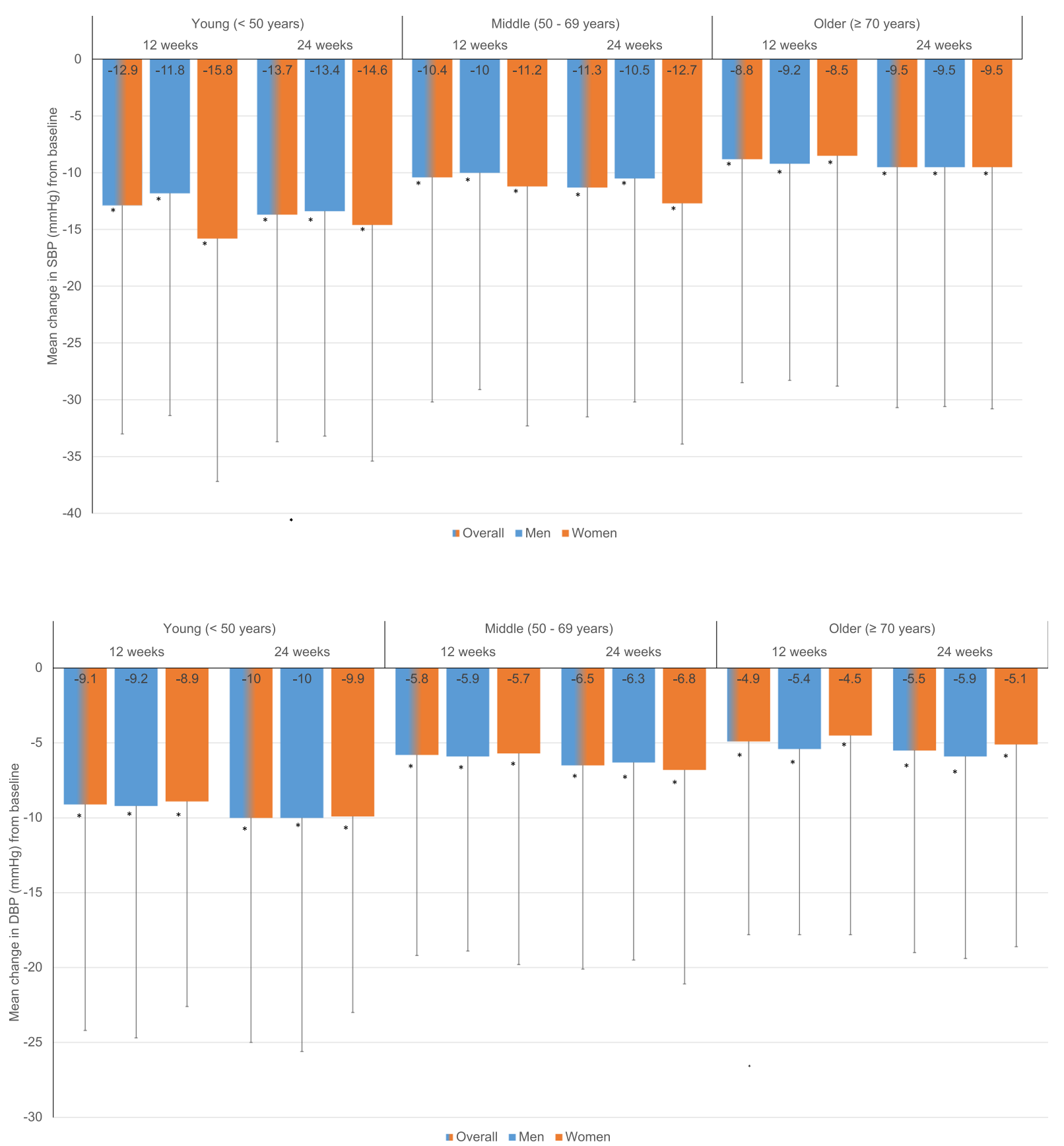

Fig. 2 Mean change from baseline in (a) systolic blood pressure (SBP), and (b) diastolic blood pressure (DBP) at 12 weeks and 24 weeks. Values are presented as mean \pm standard deviation (SD). Paired t-test; $P<0.05$ significance; ${ }^{*} P<0.001$ compared to baseline

Studies evaluating age and sex differences in the efficacy and safety of nebivolol in patients with hypertension are scarce. A retrospective analysis of three randomized controlled trials found that nebivolol monotherapy is efficacious and well tolerated across age groups; however, the efficacy in reducing SBP diminished in patients $>62$ years of age [23]. In another study in patients with type 2 diabetes mellitus and hypertension, nebivolol significantly reduced SBP and DBP to a similar extent in both males and females, with a decreasing effect seen with advancing age [24]. In our subanalysis of the BENEFIT-KOREA cohort, nebivolol demonstrated similar efficacy across sex and age in terms of reducing SBP, DBP, and pulse rate in Korean patients with essential hypertension. 


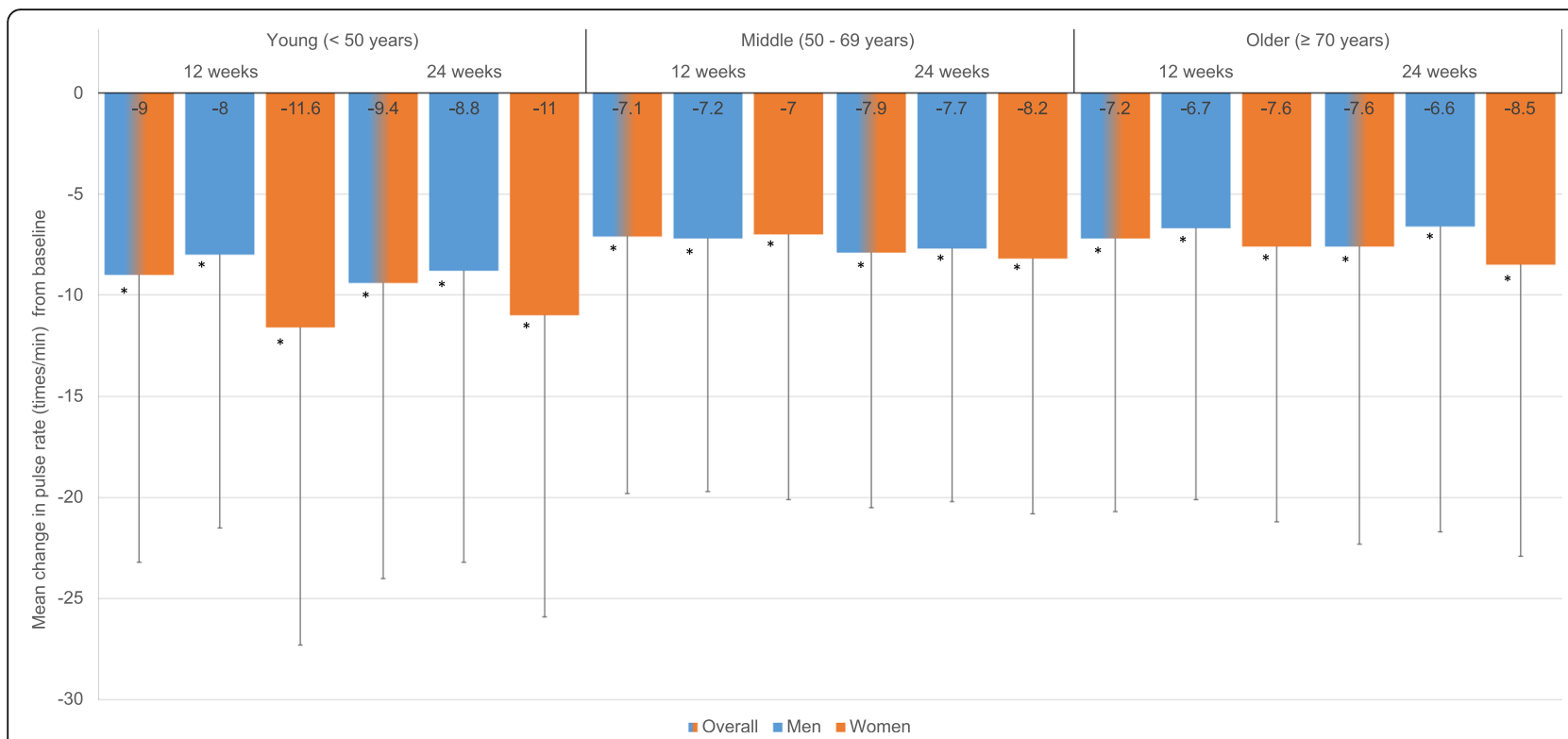

Fig. 3 Mean change from baseline in pulse rate after 12 and 24 weeks; Values are presented as mean \pm standard deviation; Paired t-test; $P<0.05$ significance; ${ }^{*} P<0.001$ compared to baseline

Increasing age is associated with increasing prevalence of hypertension in females, particularly in the sixth decade and beyond $[4,8,9]$. We observed an increasing prevalence of hypertension with age in females in the BENEFIT-KOREA cohort, with the highest prevalence seen the older age group ( $\geq 70$ years). Several factors have been suggested to be associated with the age and sex differences in the BP levels, including sympathetic tone [15]. It can be hypothesized that the effect of betablockers on sympathetic tone is mediated by a direct action on presynaptic $\beta$-receptors [25]. A study comparing the effects of nebivolol versus atenolol on autonomic function concluded that nebivolol attenuates sympathetic tone similar to atenolol, with the increased bioavailability of nitric oxide by nebivolol serving as a stimulus to inhibit sympathetic outflow [26, 27]. In our subanalysis, nebivolol, a vasodilatory $\beta 1$-adrenergic receptor antagonist, was found to be safe and efficacious in all patients with hypertension with or without comorbidities, regardless of age and sex.

Table 4 AEs and ADRs in the safety population in BENEFITKorea study

\begin{tabular}{llllll}
\hline Age $(\mathbf{y r})$ & Male & & & Female & \\
\cline { 2 - 3 } & AE & ADR & & AE & ADR \\
\hline Young, $<50$ & $26(7.2)$ & $2(0.6)$ & & $18(14.5)$ & $3(2.4)$ \\
Middle-aged, 50-69 & $125(12.8)$ & $10(1.0)$ & & $83(16.3)$ & $8(1.6)$ \\
Older, $\geq 70$ & $84(15.7)$ & $6(1.1)$ & & $115(18.1)$ & $7(1.1)$ \\
\hline
\end{tabular}

Values are presented as number (\%)

$A E$ adverse event, $A D R$ adverse drug reaction
We observed that the total dose of nebivolol administered to the study participants was significantly lower in females and in older patients. Despite sex differences in hypertension, the treatment guidelines for hypertension do not differ by sex [3]. However, in Korea, physicians tend to prescribe lower dose of medications to females compared with males, potentially to account for the differences in body weight. Older patients are also prescribed lower doses of nebivolol in clinical practice versus younger patients to account for potential renal impairment issues with advancing age (even in the absence of disease) which could lead to reduced drug clearance in turn leading to an effect of equivalent drug concentration despite the lower dose [28, 29].

This analysis is based on an observational cohort. Also, a majority of the patients in this subanalysis were $\geq 50$ years of age, so there is a limited generalizability of the study findings to a younger group of patients $(<50$ years). Despite these limitations, we believe that our subanalysis demonstrated the efficacy and safety of once-daily nebivolol across age groups with no between-sex differences.

\section{Conclusions}

Our subanalysis from the real-world BENEFIT-KOREA study shows that nebivolol demonstrated similar efficacy across sex and age in terms of reducing SBP, DBP and pulse rate in Korean patients with essential hypertension.

The prevalence of hypertension is known to differ by age and sex. Nebivolol has been reported to be efficacious and well tolerated for achieving BP control in patients with hypertension in randomized studies as well 
real-world observational studies [16, 17]. However, studies investigating age and sex differences in the efficacy and safety of nebivolol in patients with hypertension are scarce - our age and sex-based subanalysis from the large, observational BENEFIT-KOREA study provides further evidence to support clinicians managing patients with hypertension.

\begin{abstract}
Abbreviations
ACE: Angiotensin-converting enzyme; ADR: adverse drug reaction; AE: Adverse event; BENEFIT-KOREA: BEnefits after 24 weeks of NEbivolol administration For essential hypertenslon patients wiTh various comorbidities and treatment environments in Korea; BMI: Body mass index; BP: Blood pressure; DBP: Diastolic blood pressure; ESC/ESH: European Society of Cardiology/European Society of Hypertension; KNHANES: Korean National Health and Nutrition Examination Survey; MedDRA: Medical Dictionary for Regulatory Activities; SBP: Systolic blood pressure; SD: Standard deviation
\end{abstract}

\section{Supplementary Information}

The online version contains supplementary material available at https://doi. org/10.1186/s40885-021-00165-3.

Additional file 1: Table S1. Adverse events (AEs) with an incidence of $\geq 0.5 \%$ in at least one of the subgroups in the safety population in the BENEFIT-KOREA study. Table S2. Adverse drug reactions (ADRs) in the safety population in BENEFIT-KOREA study.

Additional file 2. list of IRB site.

\section{Acknowledgements}

We thank Dr. Suyog Jain (A. Menarini) for his valuable input to the manuscript and Heejung Ko for his assistance in conducting statistical analysis. We would also like to thank In Vivo Communications (Asia) for their editorial assistance for this manuscript.

\section{Authors' contributions}

KIC, DWJ, HSA, DKJ, HSL, JYL, HSL, AJM, and SWR were study investigators, made substantial contributions to the acquisition, analysis and interpretation of data, were involved in the preparation of the manuscript, and provided critical revision for intellectual content. SWP contributed to the analysis and interpretation of data, was involved in the preparation of the manuscript, and provided critical revision for intellectual content. All authors read and approved the final manuscript.

\section{Funding}

The study was funded by A. Menarini Korea Ltd.

\section{Availability of data and materials}

The datasets used and/or analyzed during the current study are available from the corresponding author on reasonable request.

\section{Declarations}

\section{Ethics approval and consent to participate}

The study was conducted in accordance with the ethical principles that have their origins in the Declaration of Helsinki. All enrolled patients provided written informed consent prior to undergoing any study-related procedure. The study protocol and relevant documentation were approved by Institutional Review Board/independent ethics committee(s) of all 66 study sites. The list of sites is included as supplementary material (Additional file 2).

\section{Consent for publication}

Not applicable.

\section{Competing interests}

AJM received honoraria for lectures from A. Menarini. SWP is an employee of A. Menarini Korea Ltd. KIC, DWJ, HSA, DKJ, HSL, JYL, HSL, and SWR declare that they have no competing interests.

\section{Author details}

'Division of Cardiology, Kosin University Gospel Hospital, Busan, Republic of Korea. ${ }^{2}$ Division of Cardiology, National Health Insurance Service IIsan Hospital, Goyang, Republic of Korea. ${ }^{3}$ Division of Cardiology, Department of Internal Medicine, Sahmyook Medical Center, Seoul, Republic of Korea. ${ }^{4}$ Division of Cardiology, Department of Internal Medicine, Soonchunhyang University Cheonan Hospital, Cheonan, Republic of Korea. ${ }^{5}$ Department of Cardiology, CHA Gumi Medical Center, Gumi, Republic of Korea. ${ }^{6}$ Division of Cardiology, Department of Internal Medicine, Kangbuk Samsung Hospital, Sungkyunkwan University School of Medicine, Suwon, Republic of Korea. ${ }^{7}$ Department of Cardiology, Ajou University School of Medicine, Suwon, Republic of Korea. ${ }^{8}$ Cardiology Department, Asklepeion General Hospital, Athens, Greece. ${ }^{9}$ Cardiovascular Center, Korea University Guro Hospital, Seoul, Republic of Korea. ${ }^{10}$ A. Menarini Korea Ltd., Seoul, Republic of Korea.

Received: 26 July 2020 Accepted: 26 February 2021

Published online: 15 March 2021

\section{References}

1. Vögele A, Johansson T, Renom-Guiteras A, Reeves D, Rieckert A, Schlender L, et al. Effectiveness and safety of beta blockers in the management of hypertension in older adults: a systematic review to help reduce inappropriate prescribing. BMC Geriatr. 2017;17(Suppl 1):224.

2. Forouzanfar MH, Liu P, Roth GA, Ng M, Biryukov S, Marczak L, et al. Global burden of hypertension and systolic blood pressure of at least 110 to 115 mm hg, 1990-2015. JAMA. 2017;317:165-82.

3. Choi HM, Kim HC, Kang DR. Sex differences in hypertension prevalence and control: analysis of the 2010-2014 Korea National Health and nutrition examination survey. PLoS One. 2017;12:e0178334.

4. Gillis EE, Sullivan JC. Sex differences in hypertension: recent advances. Hypertension. 2016;68:1322-7.

5. Williams B, Mancia G, Spiering W, Agabiti Rosei E, Azizi M, Burnier M, et al. 2018 practice guidelines for the management of arterial hypertension of the European Society of Hypertension and the European Society of Cardiology: ESH/ESC task force for the Management of Arterial Hypertension. J Hypertens. 2018;36:2284-309.

6. Chow CK, Teo KK, Rangarajan S, Islam S, Gupta R, Avezum A, et al. Prevalence, awareness, treatment, and control of hypertension in rural and urban communities in high-, middle-, and low-income countries. JAMA. 2013;310:959-68.

7. Chu SH, Baek JW, Kim ES, Stefani KM, Lee WJ, Park YR, et al. Gender differences in hypertension control among older Korean adults: Korean social life, health, and aging project. J Prev Med Public Health. 2015;48:38-47.

8. Gudmundsdottir $\mathrm{H}$, Høieggen A, Stenehjem A, Waldum B, Os I. Hypertension in women: latest findings and clinical implications. Ther Adv Chronic Dis. 2012;3:137-46.

9. Hage FG, Mansur SJ, Xing D, Oparil S. Hypertension in women. Kidney Int Suppl. 2013:3:352-6.

10. Muiesan ML, Salvetti M, Rosei CA, Paini A. Gender differences in antihypertensive treatment: myths or legends? High Blood Press Cardiovasc Prev. 2016;23:105-13.

11. Benjamin EJ, Virani SS, Callaway CW, Chamberlain AM, Chang AR, Cheng S, et al. Heart disease and stroke statistics-2018 update: a report from the American Heart Association. Circulation. 2018;137:e67-492.

12. Kim HC, Ihm SH, Kim GH, Kim JH, Kim Kl, Lee HY, et al. 2018 Korean Society of Hypertension guidelines for the management of hypertension: part Iepidemiology of hypertension. Clin Hypertens. 2019;25:16.

13. Everett B, Zajacova A. Gender differences in hypertension and hypertension awareness among young adults. Biodemography Soc Biol. 2015;61:1-17.

14. Mancia G, Grassi G. The autonomic nervous system and hypertension. Circ Res. 2014;114:1804-14.

15. Baker SE, Limberg JK, Dillon GA, Curry TB, Joyner MJ, Nicholson WT. Aging alters the relative contributions of the sympathetic and parasympathetic nervous system to blood pressure control in women. Hypertension. 2018;72: $1236-42$.

16. Olawi N, Krüger M, Grimm D, Infanger M, Wehland M. Nebivolol in the treatment of arterial hypertension. Basic Clin Pharmacol Toxicol. 2019;125: 189-201.

17. Shin J, Choi YJ, Hong GR, Jeon DW, Kim DH, Koh YY, et al. Real-world efficacy and safety of nebivolol in Korean patients with hypertension from the BENEFIT KOREA study. J Hypertens. 2020;38:527-35. 
18. Lee HY, Shin J, Kim GH, Park S, Ihm SH, Kim HC, et al. 2018 Korean Society of Hypertension Guidelines for the management of hypertension: part IIdiagnosis and treatment of hypertension. Clin Hypertens. 2019;25:20.

19. Flather MD, Shibata MC, Coats AJ, Van Veldhuisen DJ, Parkhomenko A, Borbola J, et al. SENIORS Investigators. Randomized trial to determine the effect of nebivolol on mortality and cardiovascular hospital admission in elderly patients with heart failure (SENIORS). Eur Heart J. 2005;26:215-25.

20. Thomopoulos C, Parati G, Zanchetti A. Effects of blood pressure-lowering treatment on cardiovascular outcomes and mortality: 14 - effects of different classes of antihypertensive drugs in older and younger patients: overview and meta-analysis. J Hypertens. 2018;36:1637-47.

21. Kallistratos MS, Poulimenos LE, Manolis AJ. Vasodilator $\beta$-blockers: a different class of antihypertensive agents? Futur Cardiol. 2014;10:669-71.

22. Van Bortel LM, Fici F, Mascagni F. Efficacy and tolerability of nebivolol compared with other antihypertensive drugs: a meta-analysis. Am J Cardiovasc Drugs. 2008;8:35-44.

23. Germino FW, Lin Y, Pejović V, Bowen L. Efficacy and tolerability of nebivolol: does age matter? A retrospective analysis of three randomized, placebocontrolled trials in stage I-II hypertension. Ther Adv Cardiovasc Dis. 2012;6: 185-99.

24. Ladage D, Reidenbach C, Rieckeheer E, Graf C, Schwinger RH, Brixius K. Nebivolol lowers blood pressure and increases weight loss in patients with hypertension and diabetes in regard to age. J Cardiovasc Pharmacol. 2010; 56:275-81.

25. Del Colle S, Morello F, Rabbia F, Milan A, Naso D, Puglisi E, et al. Antihypertensive drugs and the sympathetic nervous system. J Cardiovasc Pharmacol. 2007;50:487-96.

26. Chiladakis JA, Georgiopoulou E, Alexopoulos D. Autonomic effects of nebivolol versus atenolol in healthy subjects. Cardiovasc Drugs Ther. 2004; 18:469-73.

27. Maffei A, Vecchione C, Aretini A, Poulet R, Bettarini U, Gentile MT, et al. Characterization of nitric oxide release by nebivolol and its metabolites. Am J Hypertens. 2006;19:579-86.

28. Denic A, Glassock RJ, Rule AD. Structural and functional changes with the aging kidney. Adv Chronic Kidney Dis. 2016;23:19-28.

29. Glassock RJ, Rule AD. The implications of anatomical and functional changes of the aging kidney: with an emphasis on the glomeruli. Kidney Int. 2012;82:270-7.

\section{Publisher's Note}

Springer Nature remains neutral with regard to jurisdictional claims in published maps and institutional affiliations.

Ready to submit your research? Choose BMC and benefit from:

- fast, convenient online submission

- thorough peer review by experienced researchers in your field

- rapid publication on acceptance

- support for research data, including large and complex data types

- gold Open Access which fosters wider collaboration and increased citations

- maximum visibility for your research: over $100 \mathrm{M}$ website views per year

At $\mathrm{BMC}$, research is always in progress.

Learn more biomedcentral.com/submissions 